\section{Langerhans Cell Histiocytosis in a 3-year Male Child}

Sir,

We report a case of Langerhans cell histiocytosis $(\mathrm{LCH})$, earlier known as histiocytosis $X$. It is a group of idiopathic disorders which is characterised by increase in number of Langerhans cells derived from bone marrow and mature eosinophils. The clinical features of $\mathrm{LCH}$ resemble those of oral findings, which are common such as gingival ulcers, enlargement of gingiva and teeth mobility. With these common resembling oral findings, it becomes difficult to diagnose $\mathrm{LCH}$. Immunohistochemistry plays an important role in confirmation of the diagnosis. ${ }^{1}$

A 3-year male toddler was referred to pediatric dentistry department for localised painful gingival swelling in lower left tooth region. Clinical examination revealed a soft erythematous gingival swelling in relation to 74,75 along with grade III mobility of associated teeth and early exfoliation of 73 . Intraoral periapical radiograph of third quadrant revealed severe bone loss with saucerization and root resorption of 74, 75. An orthopantamograph (OPG) was advised to assess the extent of bone loss. OPG revealed osteolytic lesion in right ramus and left body of mandible with floating 74 and 75 .

Severe bone loss with early exfoliation of deciduous teeth indicated of a generalised osteolytic disease. To rule out generalised osteolytic disease, the whole body X-rays were obtained. X-ray skull revealed a punched out radiolucent lesion in frontal region.

Clinical findings involving multiple bones and factors like the age of the patient were suggestive of a fibro-osseous disease or Langerhans cell histiocytosis. A representative surgical specimen was obtained from gingiva in respect to 74 and 75 with the bone marrow aspirate for pathological assessment. Moreover, computed tomography scans of lower jaw were obtained to assess the size of osteolysis. CT and 3D-CT slides revealed large punched out osteolytic lesion with root resorption in relation to 74 .

The biopsy specimen showed infiltrate of large, openfaced nucleated histiocytes, with granulation tissue formation along with osteoclastic activity with specs of scattered bone. The superficial areas showed eroded epithelium, ulceration, necrosis and heamorrhage (Figure 1). In the bone marrow aspirate, the presence of premature histiocyte was noted, which led to the diagnosis of histiocytosis. Further, the tissue showed strong immunopositivity for S-100 and CD1a. The CD1a marker positivity confirmed the diagnosis of Langerhans

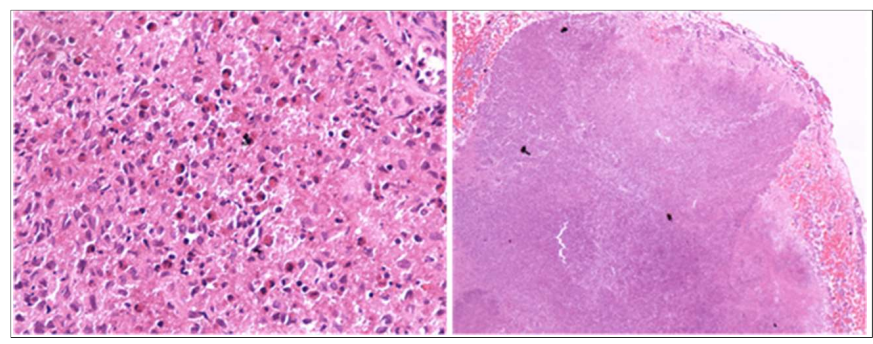

Figure 1: Section showing granulation tissue formation along with large infiltrate and open-faced nucleated histiocytes.

cell histiocytosis. The patient was treated surgically along with removal of 74 and 75 .

Thus, the common oral findings should be assessed carefully. If the symptoms do not subside with treatment, biopsy should be taken. For confirmation of $\mathrm{LCH}$, immunohistochemistry plays a very important role. ${ }^{2}$

\section{CONFLICT OF INTEREST:}

Authors declared no conflict of interest.

\section{AUTHORS' CONTRIBUTION:}

NG, RD, PA: Substantial contributions to the conception or design of the work; or the acquisition, analysis, or interpretation of data for the work.

$\mathrm{BC}$ : Drafting the work or revising it critically for important intellectual content; agreement to be accountable for all aspects of the work in ensuring that questions related to the accuracy or integrity of any part of the work are appropriately investigated and resolved.

MB: Final approval of the version to be published.

\section{REFERENCES}

1. Kumar YP, Agrawal J, Mohanlakshami J, Kumar PS. Langerhans cell histiocytosis revisited: Case report with review. Contemp Clin Dent 2015; 6:432-6.

2. Morimoto $A$, Oh $\mathrm{Y}$, Shioda $\mathrm{Y}, \mathrm{Kudo} \mathrm{K}$, Imamura T. Recent advances in Langerhans cell histiocytosis. Pediatr Int 2014; 56:451-61.

Neha Guptal, Remana Dandamudi², Piyush Arora ${ }^{3}$, Betina Chandolia 4 and Manas Bajpai ${ }^{4}$

1 Department of Pedodontics, Gitam Dental College, Visakhapatnam, Andhra Pradesh, India

2 Department of Pediatrics, Little Stars Children Hospital, Hyderabad, India

3 Department of Oral Pathology, Jodhpur Dental College, Jodhpur, Rajasthan, India

4 Department of Oral Pathology, NIMS Dental College, Jaipur, India

Correspondence to: Dr. Betina Chandolia, Department of Oral Pathology, NIMS Dental College, NIMS University, Jaipur, India E-mail: drbetina24@gmail.com

Received: July 05, 2019; Revised: April 01, 2019;

Accepted: April 06, 2019

$$
\text { .......... }
$$

